\title{
Signal processing of the galvanic skin response to quantitatively assess aspects of the educational process Theodoros Pierratos* and Hariton Polatoglou
}

Address: Department of Physics, Aristotle University of Thessaloniki, Greece

* Corresponding author

from International Society on Brain and Behaviour: 3rd International Congress on Brain and Behaviour

Thessaloniki, Greece. 28 November - 2 December 2007

Published: 17 April 2008

Annals of General Psychiatry 2008, 7(Suppl I):S233 doi:I0.II86/I744-859X-7-SI-S233

This abstract is available from: http://www.annals-general-psychiatry.com/content/7/SI/S233

(C) 2008 Pierratos and Polatoglou; licensee BioMed Central Ltd.

\section{Background}

Galvanic skin response has a long history and is regularly employed to objectively assess along with other psychophysiological responses the state of arousal, emotions and as well as cognitive activity [1]. It is a relatively simple and not invasive method and can be applied with little disturbance to subjects. With the advent of electronics it is possible to continuously measure the galvanic skin response, store it in a computer and apply signal processing to extract valuable information [2],[3]. At the same time the computer can be utilized to deliver the stimuli to the subjects thus allowing flexibility, uniformity, a variety of stimuli and combinations of them. In education most of the research is done using subjective tools and many times not concurrently, to assess the various pertinent aspects, like interest, attention, etc. The aim of the present work is to utilize the galvanic skin response of students both at high school and at the university using various stimuli related to the education processes, do signal processing to the resulted time series and device indicators that will describe the objective response of the students.

\section{Materials and methods}

To achieve this we have setup a series of stimuli, optical, auditorial and combinations related to situations in the classroom, recorded the response from a number of students by delivering the stimuli through a computer, and processed the signal. From the processing the characteristics of the signal have been isolated and a set of indicators to quantify them has been introduced [4].

\section{Results}

This research project will conclude in two steps. Here we present results from the first step which comprise of the experimentation on a small number of subjects to determine a set of stimuli appropriate for the educational case, the study of the time series and the device of quantitative indicators. We find that it is possible to find a suitable set of stimuli to access the educational process. The time series in general comprises of pink noise and the response to the delivered stimuli, thus one can perform a deconvolution to obtain the response. We have tried various quantitative measures of the response and found an indicator which describes a major part of the response. According to this indicator all subjects of this phase showed a clear tendency to habituation.

\section{Conclusions}

Our results suggest that there is great potential for using physiological metrics to model emotional experience and cognitive activity, specifically to access the educational process. Experimenting on a small number of subjects we have produced a package of stimuli, signal processing method to isolate the response to stimuli and an appropriate quantitative indicator. The next step is to apply the method to the actual training of pre-service physics teachers.

\section{References}

I. Kim K. H., Bang S. W., Kim S. R.: Emotion recognition system using short-term monitoring of physiological signals, Medical \& Biological Engineering \& Computing. 2004, 42:419-427.

2. Wagner J., Kim J., Andre E.: From Physiological Signals to Emotions: Implementing and Comparing Selected Methods for 
Feature Extraction and Classification. IEEE International Conference on Multimedia \& Expo (ICME 2005) 2005.

3. Donadio V., Karlsson T., Elam M., Wallin B. G.: Interindividual differences in sympathetic and effector responses to arousal in humans Journal of Physiology. 2002, 544(I):293-302.

4. Mandryk R.L., Inkpen K.: Physiological Indicators for the Evaluation of Co-located Collaborative Play. In Proceedings of Computer Supported Cooperative Work (CSCW 2004) Chicago, IL, USA.

Publish with Bio Med Central and every scientist can read your work free of charge

"BioMed Central will be the most significant development for disseminating the results of biomedical research in our lifetime. "

Sir Paul Nurse, Cancer Research UK

Your research papers will be:

- available free of charge to the entire biomedical community

- peer reviewed and published immediately upon acceptance

- cited in PubMed and archived on PubMed Central

- yours - you keep the copyright

Submit your manuscript here:

http://www.biomedcentral.com/info/publishing_adv.asp 